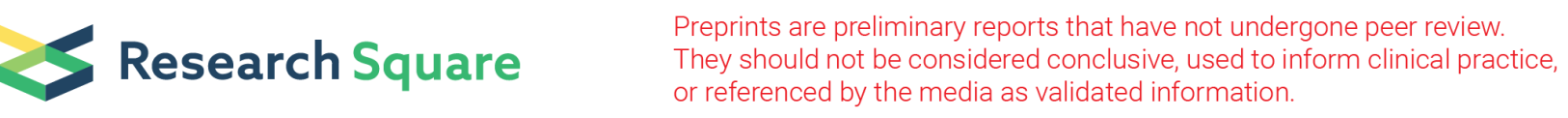

\title{
A Realist Evaluation of Senior Medical Students' Perspective of a One-Week A Residential Aged Care Facility Clerkship
}

Janette Christine Radford ( $\sim$ J.Radford@utas.edu.au )

University of Tasmania College of Health and Medicine https://orcid.org/0000-0002-5751-0488

Marguerite Bramble

Charles Sturt University

Anne Todd

University of Tasmania

Research article

Keywords: Residential aged care, medical student, realist evaluation, general practice, clerkship

Posted Date: December 15th, 2020

DOI: https://doi.org/10.21203/rs.3.rs-127873/v1

License: (c) (1) This work is licensed under a Creative Commons Attribution 4.0 International License.

Read Full License 


\section{Abstract}

Background: Residential aged care facilities (RACFs), also known as nursing or aged care homes are infrequently used to deliver experience-based learning to medical students.

Methods: This is a realist evaluation of senior medical students' perspective of a one-week clerkship delivered in RACFs seeking to find what aspects of their clerkship worked for whom and why as part of the evaluation of the clerkship. This is a qualitative study using written and focus group data.

Results: The highly structured curriculum delivered many positive learning outcomes for students such as practice in improving management of end-of-life and dementia care, an understanding of how RACFs functioned, and a chance to participate in interprofessional practice. The context also challenged some students who struggled to see the relevance of the clerkship in relation to their personal and/or professional identities.

Conclusions: The realist evaluation builds on a previous theory of experience-based learning adding a student intraindividual aspect to the theory to better define the mechanisms involved. The resulting realist theory of experience-based learning may prove useful to other studies of experience-based learning.

\section{Background}

The use of residential aged care facilities (also known as nursing homes or care homes) to provide healthcare professional clerkships (clinical learning opportunities within clinical workplaces) for students has been variable over recent decades depending on the country and the health care professional group considered. Residential aged care facilities (RACFs) is the Australian term and traditionally medical students have not undertaken clerkships in these facilities. We report on the student perspective of a oneweek clerkship for final year medical students that has broken that trend with a sustained programme since 2011 (1). This study is a realist evaluation (2) aiming to understand, from the student perspective, which aspects of the programme were acceptable or not acceptable, and why this was so.

Residential aged care facilities provide respite or permanent care for frail or disabled people who can no longer live in their own homes, combining residential, personal, psychosocial, and clinical nursing care. The 'teaching nursing home' (TNH) is a USA-based innovation introduced in the 1960 s by physicians (3), which became popular in the 1980s (4) with about 90 percent of USA medical schools using them for selective or elective teaching programmes for senior medical students or mandatory resident placements under the supervision of internists or family physicians (5). The traits of the TNH have been described as an affiliation between a nursing home and an academic institution offering a "synergy between education, research and clinical care" (6)(p. 507).

Medical education activities described in USA-based TNHs have included the provision of introductory teaching on the medical interview and physical diagnosis to early stage medical students, which was found to be of equal validity to hospital- based patients despite a lack of acute diagnostic issues (7); 
medical rounds, used as teaching experiences, on outreach visits by hospital-based geriatrics teams (8), and short structured learning experiences within primary care rotations (9). Curriculum topics relevant to care of a RACF population have been noted to include delirium, dementia, pain, falls, polypharmacy, and end-of-life care (3). It seems that support for medical education engagement within TNHs in the USA has waned in recent times perhaps due to funding issues (10) leading to a call for re-engagement (11). There is some evidence this is occurring, often aiming to deliver interprofessional learning opportunities for students (12).

In the Netherlands nursing homes have provided clerkships for early-stage medical students (13), and for senior medical students (14). In 2011 Australian TNHs were a new concept with an emphasis on providing clerkships for nursing undergraduates with few reports of medical student clerkship placements (15). Since the University of Tasmania programme began RACF-based learning activities of shorter duration (16), or less embedded as a clerkship, have been delivered in Australia (17).

This paper describes a realist evaluation of senior Australian medical students' perspectives of an innovative one-week clerkship in a RACF leading to a realist-experience-based programme theory that may be replicable in other clerkship contexts .

The initial programme theory:

The initial programme theory was that a well-supported, highly structured one-week clerkship for groups of two to five, final-year medical students in a RACF providing real-patient learning would lead to studentvalued learning outcomes, despite lack of full-time, on-site general practitioner (GP) supervision. The programme theory was consistent with Dornan et al's(2007) experience-based learning model (18) and (2014) experience-based learning theoretical framework (19). Students were expected to actively participate in the care of RACF residents being at all times supported to do so by nurse mentors (1).

Evaluation questions:

The evaluation questions were "does a one-week placement for senior medical students in an Australian RACF a) provide student-valued learning experiences? If so, why and if not, why not?"

Student feedback was combined with RACF staff, GP tutor and academic evaluation to finesse the programme over two years. The programme continues to this day (1).

\section{Ethics approval:}

Ethical approval was obtained from the Human Research Ethics committee (Tasmania) network (No.H11576). Informed consent was obtained from study participants in writing.

\section{Methods Section}

Rationale for using a realist evaluation: 
Realist evaluation was chosen as a pragmatic theory-based approach avoiding the "epistemological poles of positivism and relativism" (2) (p. 5). It sits between the positivist stance that there is a mindindependent reality and the constructivist stance that 'reality' is unknowable (20) and seeks to "answer the question of what works for whom in what circumstances" (2) (p. 125). Realist evaluation combines a belief in a mind-independent reality (context) with acknowledgement of its effect on human responses (mechanisms) leading to outcomes. Realist analysis of empirical case studies seeks outcomes linked to mechanisms triggered by aspects of external reality (context) leading to the identification of contextmechanism-outcome configurations (CMOCs) (20). The aim is to improve a programme's theory via a deeper understanding of programme context, mechanism, and outcome patterns (2).

Realist evaluation aims for continual improvement of practice rather than universal truths, however empirical generalisations or demi-regularities can be drawn that help build or refine theory (21). So, while a programme will work differently in different contexts the theory-based understanding of 'what works for whom, in what context, and how' is more widely applicable (22). As in this study an initial programme theory is often based on a mid-range theory to develop a programme rather than developing a programme from scratch. Mid-range theories, in turn, are usually a subset of a unified social theory (2). In this study Dornan et al's experience-based learning theoretical framework (ExBL) has been used as a midrange theory $(18,19)$ which is a subset of Lave and Wenger's 'community of practice' social learning theory $(23,24)$. As Cruess et al $(2018)$ argue the 'community of practice' learning theory provides a comprehensive, foundational theoretical framework for medical education as learners acquire the identity of a medical practitioner and accept medical culture's norms (25).

The ExBL theoretical framework resulted from a review of the literature to describe the conditions, processes and outcomes of undergraduate, medical students' clerkships (19) and was an elaboration of a previous model (18). The categories that were developed by Dornan et al (2014) for the ExBL theoretical framework were not presented as CMOCs (19).

Taking an iterative approach to data-analysis and subsequent theory refinement initially using an elaborative, or top-down, coding approach (26), based on Dornan et al's mid-range theory (19) CMOCs were identified specific to medical students' perspective of the RACF programme while developing a realist experience-based learning programme theory that is potentially relevant to generic clerkship placements.

Viewing ExBL codes from a realist evaluation perspective mostly results in a reconfiguration of ExBL's conditions, processes and outcomes into context, mechanism, and outcome categories.

Context contains all the environmental aspects in which a learning programme is delivered $(27,28)$. Context includes prevailing beliefs, social and cultural norms, regulatory and economic forces (20). Realist mechanisms are usually hidden, sensitive to variations in context, and generate outcomes (29). Depending on the range of the intended explanation of a realist evaluation, the mechanisms described may be conceptualised as explaining large-scale social transformations or individual reasoning and responses (30). An inclusive definition is "a mechanism is an element of reasoning and reactions of (an) 
individual or collective agent(s) in regard of the resources available in a given context to bring about changes through the implementation of the intervention" (31) (p. 8). Outcomes include the intended and unintended consequences of an intervention (32).

The complex intervention of medical education is particularly suited to realist evaluation due to the iterative programme theory-building process that realist methods support (20). As Wong et al (2012) note in medical education the question may be "what kinds of educational interventions will tend to work for what kinds of learners, in what kinds of contexts, to what degree, and what explains such patterns?" (20) (p. 93). Realist programme evaluation also answers the call for better health professions education programme evaluation than to answer the question 'did it work'? (33).

In this study outcomes include each student's global evaluation of, claimed learning outcomes from, or reported learning experience of their RACF clerkship. Mechanisms account for outcome variation as each student responds to their perception of their context. All mechanisms in this analysis are embodied in the student i.e. they are intraindividual. The context triggering a mechanism was a student's experience of the clerkship in the RACF which was nested within the wider context of their medical education, which is nested within their total environmental context.

Environment surrounding the evaluation:

Australian RACFs provide care for $9 \%$ of Australians. The medical care provided is complex and challenging with $70 \%$ of residents 80 years or older, $90 \%$ dying in the facility, and $40 \%$ of permanent residents dying within a year of admission. The medical problems managed are mixed with $52 \%$ of permanent residents having dementia, 25\% a mental illness, $25 \%$ cardiovascular disease, $17 \%$ musculoskeletal and connective tissue disease (34).

In Australia, general practitioners (GPs) (family or primary care physicians) manage the medical care of RACF residents. The GP caring for a RACF resident usually conducts their main practice off-site, visiting the RACF routinely and/or on an as-needs basis (35).

The RACF system of healthcare delivery is seen as under strain in Australia due to factors such as too few and/or poorly trained nursing and care staff, poor availability of GP-emergency and after-hours care, and poor remuneration of RACF healthcare professionals (36). This resource-poor environment may also have to deal with the unrealistic expectations of family members or residents for curative care when a more palliative approach is warranted, as in the care of people with end-stage dementia. The skills to deliver a more appropriate palliative approach may also be lacking (37-40).

Description of the programme evaluated:

The development of the novel programme was undertaken to expose senior medical students to the unique clinical environment of an RACF while also highlighting explicit learning outcomes related to the care of elderly, frail patients. In particular the placement aimed to give students experience in dementia care, and palliative care for patients including those with dementia. 
The clerkship was highly structured to overcome the lack of hour-by-hour on-site supervision by a GP and to ensure the safe care of the residents with whom students' worked.

No curriculum existed for medical learners delivering care for RACF residents (41) so various curricula or other resources were adapted to guide the initial development of the one-week placement (42-44).

A GP tutor, whose patients the students engaged with, met students for two hours at the beginning of the day in the RACF, and students reported progress at the GP's practice at the end of the day. The GP directed student activity, delivered tutorial topics, assessed progress, and gave feedback. Nursing staff were employed and trained to mentor health professional students within the RACF, including the medical students (45). The nurses worked closely with the GP tutor and co-supervised the medical students. Opportunities for interprofessional learning were hoped for where medical student placement weeks coincided with nurse and/or paramedic clerkships.

Students were orientated to the placement with a three-hour workshop on the characteristics of people who lived in RACFs and the medical management of the frail elderly who may have dementia and need a palliative approach to their care.

The placement was contextualised to students' impending role as hospital interns noting that all would be caring for in-patients who had either been transferred from an RACF before admission or be transferred to RACFs after an in-patient stay. Understanding the context of their prospective patients' care would therefore aid the care they delivered as interns.

RACF residents, or their guardians, prospectively consented residents to participate in the programme. Resident safety was of paramount importance in curriculum design. The highly structured programme required students to cooperate with peers to practise their comprehensive clinical assessment skills with residents. The syllabus for the clerkship was the Royal Australian College of General Practitioners "Silver Book" (42).

The clerkship programme was also scaffolded (46) to enhance the students' skill acquisition over the course of the week. The residents assessed had no co-morbid dementia at the beginning of the week. The second day involved assessing residents with mild to moderate levels of dementia. By the third- or fourthday students assessed residents with severe dementia, many of whom resided in a secure unit to optimise the management of behaviour such as wandering.

The lead author(JR) worked with a key GP tutor to devise the initial curriculum, and third author (AT) assisted with the development and supervision of student-engaged clinical audits. All worked closely with RACF staff on the design of the programme.

The initial evaluation design:

The evaluation involved student focus groups undertaken on day four of the five-day placement, and of written feedback collected at the end of the week. The written feedback asked students to provide a 
global rating for the placement ranging from poor to excellent and asked them to note why they rated the placement as they did, what worked well with the placement and what worked poorly and how the placement could be improved. The written feedback provided weekly advice to the programme developers, whilst the focus-group interview data added another dimension to the written feedback at sixmonthly intervals. All data were used to refine the initial programme theory.

Recruitment process:

All students were invited to participate and consented by academics independent of student assessment. All but two students participated in the evaluation.

\section{Data analysis:}

Written feedback forms were deidentified and transcribed. Focus group interviews were audio-recorded, transcribed and deidentified. The texts were initially coded using Dornan et al's experience-based learning (ExBL) theoretical framework for clerkship education (p. 735-6) (19) which was organised into clearer numbered codes. (see supplementary file 1). Excel (47) spreadsheets were used to identify codes and, subsequently, context-mechanism-outcome configurations.

The process of analysis, theorising and developing CMOCs was iterative taking a retroductive approach to theory refinement i.e. both inductive and deductive logic was used as well as insights and hunches (48). The iterative process involved elaborative coding of text-based data based on the ExBL theoretical framework [2014 dornan] with new concepts added to that framework, and the identification of CMOCs.

The coding of both types of data was undertaken initially by JR, then reviewed by MB, and AT with discussion leading to final agreement. Acknowledging reflexivity we are a multidisciplinary team with JR a clinical educator, a GP who cares for RACF residents, and a cognitive behavioural therapist; MB a registered nurse and research project officer; and AT a pharmacist and clinical educator who has conducted medication reviews for RACF residents.

The report meets realist evaluation reporting standards (49) and qualitative research reporting standards (50).

\section{Results}

Details of participants:

Participants were final (fifth) year medical students studying an undergraduate degree in Australia. Their expected trajectory would be to work as interns the year after the RACF clerkship. Twenty students undertook the placement in 2011, 41 in 2012 and, 18 in 2013.

Main findings: 
The findings are presented in three sections though this does not reflect the iterative, retroductive nature of analysis. The first section presents elaborative coding of data. The second presents a finessed experience-based learning programme theory. The third presents findings as 'context-mechanismoutcome configurations' leading to a final output presented in the discussion of a realist theory acknowledging the non-linear, emergent, and dynamic nature of clerkship experienced-based learning. See figure one as a representation of the analysis process and outcomes.

Results Sect. 1 - Elaborative coding of data

Data were coded against the ExBL theoretical framework(19) using an elaborative coding process (26) leading to the confirmation of many ExBL codes and new codes. Data examples against codes are given in the following table. Some data examples denote contrasting statements highlighting the range of student views about the RACF clerkship. New codes are italicised. Focus group data are denoted, other data are from written feedback. The year and week denote the time the data were collected. 


\section{ExBL codes. Representative data (from medical students)}

Experienced real patient learning (RPL)
"It has been useful performing the medical assessments and actively contribute to the care of patients". (2011, wk 2)

\section{Experienced} affective learning $(A L)$

Practical learning: Knowledge $(\mathrm{K})$
"It is nice to feel a bit valued" \& "It makes you feel a bit more confidence in your knowledge". (focus group) (2011, wk2) "..it has been a really good supplement to the general medical rotation because a lot of our patients are elderly with dementia and have come in from nursing homes and things like that, but they are getting treated acutely. Whereas this

helps you learn about what you treat acutely and what you don't treat, if that makes sense, in elderly people." (focus group) $(2011$, wk2)

"Like maybe they don't need all this stuff because they are going into a nursing home and they are old, and their quality of life is poor and maybe they don't want to be taking 20 tablets in the morning ". (focus group) $(2011, w k 2)$

Practical learning: Skills $(\mathrm{S})$

\section{Practical}

learning:

Attitudes (A)

Practical

learning: study

skills

Interprofessional

learning (IPL)

Instructional design (ID)
"It will be useful, I feel next year [intern year]. I feel like some of the skills that we have learnt about making decisions or just talking to elderly people would make it a bit easier on the wards." (focus group) $(2011$, wk2)

"Yes, it has been really, really good to see how your attitude to treating somebody in their last few years of life is different to treating acutely because we are so used to acute treatment, so that has been really valuable." (focus group) (2011, wk2)

"..and stuff that we don't come across elsewhere. Like the sessions having a pharmacist and a GP to discuss things, like people's medicines and stuff like that has been really useful.. " (focus group) (2011, wk2)
Observing (0)

Rehearsing ( $\mathrm{R})$

Contributing to real patient care (CAPC)
"Very well-orchestrated, and like, it has been put together well. Often on the wards you are on this team and 'go find your way and work out what you are going to fill your day with, work out how much you want to do, where you want to be.' We ask to do stuff, but you may just be ignored for the whole day depending on who you end up with and I think that is just definitely not the case here. " (focus group) $(2011, w k 2)$

" just seeing a nurse how they deal with someone talking absolute rubbish and how they just talk to them and sort of change their thinking". (2012,wk1)

"Morning talks with GP XXX worked well. He discussed things as though we were interns in the [local hospital], and asked us how we would handle different situations". (focus group) (2011, wk4)

"And I think that our opinions can be... like the sessions we have had where we have done a CMA and discussed it with the GP, I have felt that what we have done was useful because they have said 'oh, you know Dr XXX said 'oh that is a good idea maybe we should reconsider that medicine or something' and it is nice to have your ...opinion considered and be able to apply all of this stuff we have been learning whereas sometimes on the general meds rotation you just don't get to use your brain at all." (focus group) $(2011$, wk2) 


\section{ExBL codes. Representative data (from medical students)}

Student

experience is

sequenced

appropriately

(ESA)

Student

experience felt

to be

appropriate to

level of

proficiency

(EAP)

Or

not EAP

Resourcing the experience (Res)

Welcomed and orientated

(W\&O)

Students understand what is expected of them (Exp)

Patient contact is arranged (PO) group)(2012,wk2)

Not something the students were likely to comment on but evident in the design and delivery of the programme
"Very little clinical oriented experience. A lot of nursing and psychological type
teaching. Not absolutely relevant for internship or resident years" (focus group)
$(2011, w k 4)$

"Very little clinical oriented experience. A lot of nursing and psychological type
teaching. Not absolutely relevant for internship or resident years" (focus group)
$(2011$, wk4)

"Very little clinical oriented experience. A lot of nursing and psychological type
teaching. Not absolutely relevant for internship or resident years" (focus group)
$(2011$, wk4)

"Better in final year than any other" ...." Initially when I was told about the programme, I thought it is really inappropriate for us, like that was my initial thought. We don't need to do this, it is not for us it is for somebody that is earlier in the course can do like third year or second year but now that I have done it, I honestly think that if I didn't know a lot of the stuff I know now then you don't get as much out of it " (focus group) (2011, wk2)

"I think the reason we have been helpful is that we know enough about the medications and the patient care, whereas in second year you are still a bit of a sponge and you are absorbing everything." (focus group) (2011,wk2)
"They want you to be here and they want you to learn and they have got things planned for you to do all day". (focus group) (2011, wk2)

"The best thing is how well organised the whole thing is, I think. It just makes a big difference when you know what's happening, what you should be doing" (focus group)(2013, wk 3)

Supervisors observe \& give feedback (O\&F)

" GP coordinator is excellent. She listened to our reports, took suggestions and corrected our errors." (2011, wk2)

Students are

“Debrief with XX [GP tutor] - excellent”. (2011, wk2)

briefed \&

debriefed (B\&D)

Small group learning (SGL)

"I think it has been good sending us out in a group of four because I think four is a good number. I am inclined to think that even six would be too many. It is just nice having the four of us and we talk to each other about each other's patients and go in to see the patient in a pair and you could go and see them by yourself but just going together is good too because one can write, and the other one can sort of ask the questions or one can pay attention to the body language and the other one will write. That has been good. I think it is nice having a small group as opposed to a bigger group. It is much more personalised, and it is a relaxed environment." (focus group) (2011, wk2)

Supervising clinicians were "what really made the week, were the morning discussions and the collegial approachable atmosphere; it wasn't like an "us and them" hierarchy". (focus group) $(2013, w k 4)$ 


\section{ExBL codes. Representative data (from medical students)}

Good

professional

behaviour was

modelled

(GPBM)

Affective support (AS)

Supervisors respectful, open etc (Resp)
No one comment illustrates this code instead it is evident from multiple comments concerning the supervising and tutoring clinicians.
Supervisors inspiring and positive (I\&P)
"Not all of your ideas are shot down immediately; you know we have a discussion about it, so it is a friendly environment." (focus group) $(2011$, wk2)

"..we're often used to being just told things and spoken at, whereas the GP will say "And what do you think about that?" and ..."What could we change and what could be done differently?" And that's really appreciated because you feel involved rather than just being spoken at." (focus group) $(2012, w k 7)$
Students made to feel part of the team (PoT)
"I guess there was a really negative perception of nursing homes and they'd be probably depressing in a way...... just not a particularly vibrant or energetic or fun environment. That, I guess, was my impression. But then I guess the staff and the carers and some of the residents too, went against what I thought initially." (focus group) $(2013$, wk4)
Enabled independent thinking $(E / T)$

Luxury of time (LUXT)

Reflective learning (Ref)
"I think seeing the patients and then discussing them in the forum that allowed you to make mock clinical decisions was probably the most valuable part of the placement, because we rarely get to do that in the culture of the acute care facility because of the medical hierarchy". (focus group) $(2013$, wk3)

"..and it is nice to have your ...opinion considered and be able to apply all of this stuff we have been learning whereas sometimes on the general meds rotation you just don't get to use your brain at all." (focus group) $(2011$, wk2)

"We get to demonstrate what we have been learning whereas sometimes you don't get a chance to do it." (focus group )(2011,wk2)

"Whereas because it's so easy-going it's almost... it makes it a lot more enjoyable. And being sort of self-paced in terms of you do a CMA, you come back here, and we write it up and we talk to each other about it and that's the best way for us to learn because...rather than having to go home and finish it that night because you didn't have enough time". (focus group) (2012,week1)

"I think one of the important perspectives you get is, you see these patients who, effectively they have a lot of medical conditions and they're losing a little bit of independence, hence why they're in these facilities, but the difference between seeing the people here and in hospital is the transformation when they put on an hospital gown, for anyone is quite amazing, I think. It's very easy to look at someone, they're all wearing the same hospital gown, they're all in the same hospital beds and I think it's very easy for you to see them as sort of medical problems. As opposed to here in the aged care centre, they're in their own gear, they're sitting in their own rooms and they're reading their own books - well yeah doing their day-to-day activities. And if you remove them from here and put them into the emergency department in the hospital, it's very easy to look at them differently.......It's very easy to just lose sight of their individuality, I guess."(focus group) $(2013, w k 1)$ 


\section{ExBL codes. $\quad$ Representative data (from medical students)}

\begin{tabular}{|c|c|}
\hline $\begin{array}{l}\text { Professional } \\
\text { identity } \\
\text { formation (PI) }\end{array}$ & $\begin{array}{l}\text { "I don't really like nursing homes but that is just me and I don't know what else } \\
\text { you are going to do to change me on that. ... to be honest it is just my mind set. I } \\
\text { think my approach to medicine, like everyone pigeonholes me as a surgeon } \\
\text { because that it this way I like to see thinks. I don't like the long drawn out gradual } \\
\text { decline that you see here. But that is purely personal". (focus group) (2012.wk5) }\end{array}$ \\
\hline $\begin{array}{l}\text { Professional } \\
\text { identity - } a \\
\text { socialised lens }\end{array}$ & $\begin{array}{l}\text { "And it's difficult for us because we've been gearing more and more during this } \\
\text { year towards acute care and we're just all geared towards that totally and I can } \\
\text { see the necessity of aged care and management of chronic illness, but it just } \\
\text { doesn't fit into our programme for me right now....".(focus group) }(2011, \text { wk5) }\end{array}$ \\
\hline $\begin{array}{l}\text { Professional } \\
\text { identity - a self- } \\
\text { authoring lens } \\
\text { (Prof.Id-Self } \mathrm{Au} \text { ) }\end{array}$ & $\begin{array}{l}\text { "This placement is not about making precise clinical decisions. It's not about } \\
\text { quickly formulating, getting a set of symptoms and a set of signs and making a } \\
\text { diagnosis. It's about understanding the needs of the patient, understanding who } \\
\text { you're working with, understanding the family's needs and, you know, making } \\
\text { decisions based on that. It's more about ... you call it community medicine, but it's } \\
\text { what like the majority of people will be doing in the future, but a lot of medical } \\
\text { students don't see the value in it, but it's actually highly valuable."(focus group) } \\
(2013, \text { wk } 3)\end{array}$ \\
\hline
\end{tabular}

Results Sect. 2 - Finessed experience-based learning theoretical framework

The iterative process of identifying $\mathrm{CMOCs}$ and revising codes led to a reordering and elaboration of the ExBL (19) codes with the addition of new codes to better enable a realist review of the data, a perspective asking "what has or has not worked for the learner, and why"?

In the reconceptualisation of the ExBL theoretical framework 'learning mechanisms' are an amalgam of Dornan's student participation in practice sub-categories and the aspect of the affective learning codes that can be viewed as intraindividual. Two additional new codes: 'independently thinking about a patient' and 'reflective learning' are also added (51).

The ExBL code of 'Condition: support' and the 'Instructional design' codes have been reconceptualised as the design and delivery of a curriculum (52-54). In realist terms part of the context for student learning.

The outcomes of learning in this conceptualisation are either externally evident by being observed by others or are claimed by the learner. This is as opposed to intraindividual mechanisms of learning that may not be evident to an observer, (nor to the learner depending on their metacognitive ability) (55).

The analysis highlights an aspect missing from the ExBL framework; the person who is the student and their 'professional identity formation'. Some have argued that professional identity formation should be considered an educational objective of medical education (56). As Cruess et al (2015) note "Those entering medical school arrive with a personal identity formed since birth........Each individual's journey from layperson to skilled professional is unique and is affected by 'who they are' at the beginning and 'who they wish to become' " (57)(p. 718). The effect of the student's personal identity, who the student feels they are and what they wish to become are all factors in how students' perceive the value of their clinical experiences, and how they engage in the learning experiences offered (58). The conceptualisation 
of professional identity stages using Kegan's model of adult development has also proved useful in coding our data $(57,59)$.

The proposed finessed experience-based learning theoretical framework for evaluating a RACF clerkship reflects or uses the wording, terminology, numbering and definitions of Dornan et al's (2014) ExBL framework (19). Added conceptualisations, and minor additions to major sections are in italics. Section four is a new section relating to student professional identity formation.

\section{Learning mechanisms (intraindividual processes) 1.a.Learning by doing: Participation in practice}

1.a.i Observing: as part of "legitimate peripheral participation" (23)

1.a.ii Rehearsing: rehearsing the task of doctors. (19)

\section{1.b. Learning by thinking (cognition)}

1.b.i Independently thinking about a patient: students are given opportunities to assess patients, draw their own conclusions and formulate a management plan. Although this could lead to contributing to authentic patient care it will depend on how the student's supervisor responds to the student's ideas. If the supervisor never elicits the student's ideas or does not seriously consider them then no contribution to patient care can occur.

1.b.iReflection: "the process of engaging the self in attentive, critical, exploratory and iterative interactions with one's thoughts and actions, and their underlying conceptual frame, with a view to changing them and a view on the change itself" $(60)(p .48)$. Encouragement to explicitly reflect can help a learner actively form their professional identity (51).

1. c. Affective Learning (intraindividual process): is "learning that includes students' emotions, mood, state of mind" (19)(p. 735).

2. Realist outcomes of learning (ExBL's practical learning and real patient learning) -learning that is evident to others as well as to students.

2.a Knowledge: "They develop an integrated understanding of how to become and be a doctor, of organisational aspects of health care, and of professional roles."(19) (p. 735)

2.b Skills: "They learn to perform skills in the context of practice. They learn how to behave towards patients and professionals and acquire new skills like applying evidence-based principles to practice." (19)(p. 735) 
2.c Affective learning (externally evident): Was originally described by Blooms' group as "Changes in interest, attitudes, and values and the development of appreciations and adequate adjustment" (61)(p. 7). In medical education this can "include confidence, motivation, reward, and a sense of legitimacy and belonging in clinical settings. Students develop a sense of themselves as future physicians. Some affects are directed towards others: qualities like compassion, humanity, empathy, idealism, and interest in and a sense of responsibility towards people"(19)(p. 735)

2.c i Attitudes: "They develop attitudes, for example, towards vulnerable people, ethical aspects of care and towards the roles of themselves, other professionals, and different medical specialties in providing care" (19)(p. 735)

2.d Study skills: "They learn how to manage their learning and learn in an interprofessional context. They learn presentation and critical appraisal skills"(19) (P.735)

2.e Real patient learning: the ultimate product of context and learning mechanisms is real patient learning: "A contextualised type of learning takes place within students' interactions with real patients. Students bridge theory with practice, contextualise, reinforce, and integrate what they have learned. They understand the complexity and spectrum of disease....." (19)(p. 735)

2.e.i Contributing to authentic patient care: providing input into the care of real patients that has the potential to make a difference to patient care. This includes performing specific care tasks.

2.f. Professional identity formation: Identity formation is "an adaptive, developmental process that happens simultaneously at two levels. (1) at the level of the individual, which involves the psychological development of the person and (2) at the collective level, which involves the socialization of the person into appropriate roles and forms of participation in the community's work" (62) (p. 1185-6). Identity formation is a key outcome of participating in a community of practice $(23,24)$.

Professional identity is "A representation of self, achieved in stages over time during which the characteristics, values, and norms of the medical profession are internalized, resulting in an individual thinking, acting, and feeling like a physician."(63) (p. 1447). The stages of professional identity formation can be understood using Kegan's model of adult development $(57,59)$. The stages describe the perspective, or lens, that people use as they integrate their experiences into their evolving professional identity (59), influencing their personal epistemologies over time (58).

Stages of professional identity formation using Kegan's model of adult development starting with the least complex epistemological lens.Lewin et al (2019) explain that "meaning-making lenses shape an individual's approach to the work, and the individual is subject to their effects, unable to see the limitations and biases the lenses bring. Transformation to a new lens occurs as the individual is confronted with new situations where the previous lens has proved to be inadequate. The new lenses subsumes the previous one, which becomes an object available to be held in the mind and examined. Kegan's model predicts that individuals further along this trajectory are more successful in responding to 
complex work and life challenges"(59)(p. 1301). The following lenses are most relevant to medical education. They represent increasingly complex epistemologies with the simplest being an instrumental lens while the self-transforming lens represents the most complex epistemology with which to construct meaning.

2.f.i -an instrumental lens: the individual takes on a professional role and is responsive to the views of others but is driven mostly by their own needs. They will tend to follow rules to optimize the attainment of their goals $(57,59)$

2.f.ii - a socialised lens: the individual is motivated by the expectations of their profession, adopting group norms of behaviour and attitudes such as altruism and sharing work obligations. They are motivated mostly by being an accepted member of their profession. $(57,59)$

2.f.iii - a self-authoring lens: the individual has a personally defined value system which is based on the professional values of the profession. This perspective permits a strategic engagement with the idealistic expectations of the profession. $(57,59)$

2.f.iv - a self-transforming lens: this stage is rarely attained and may not be reached until later adulthood. The individual can deal with the complexity of multiple perspectives flexibly though still possessing a solid value system. They may seek other perspectives to broaden understanding. (59)

\section{Curriculum design and delivery (ExBL's instructional design and condition: support)}

Context has two aspects: one is external to the student and involves curriculum design and its delivery, the other involves what the student brings to the learning context, i.e. is intraindividual, within the student.

\section{Context external to the student}

Instructional design is the organisation of opportunities to enable student learning while engaged in a clerkship (19). It can vary from placing a student within a clinical environment and hoping they have a useful learning experience to explicitly structuring their relationships with their supervisors and patients, and their activities whilst undertaking their clerkship. The RACF placement was an example of the latter approach.

For delivering the curriculum three factors are required to work well together; a well-designed curriculum, a clerkship capable of delivering the curriculum, and support for the student to make the most of their learning experience. These factors are teased out:

\section{3.a Planning experience at curriculum level:}

3.a.i Devising or revising curricular, adding new components. A prescriptive, or written, curriculum should be developed, then a deliberative approach adopted to refining it. All should be couched in a critical 
exploratory framework so that decisions are made about a clerkship placement based on what type of clinician the learner needs to become for the sake of the future health care needs of a society. (52-54)

3.a.ii Student experience should be sequenced appropriately "ensuring participatory experiences that are appropriate to their current level of proficiency" (19)(p. 735)

3.a.iii Enough time is given for optimal learning

3.b Resourcing experience at curriculum level: This concept covers adequate fiscal support to deliver a curriculum, providing enough teaching room, and ensuring teaching time availability. It also covers giving students access to an appropriate range and mix of clinical experiences of authentic patient care, while providing adequate supervision (19)

3.c Delivering experience at placement level(19)3.c.i Welcoming and orientating students

3.c.ii Making clear what is expected of them

3.c.iii Arranging opportunities to meet relevant patients

3.c.iv Organising activities that are conductive to education and optimise participation

3.d Formally supporting individualised learning. (19)

3.d.i Supervisors observe students and give feedback

3.d.ii Supervisors brief and debrief students

3.d.iii Complements to on-the-job experience are provided like

3.d.iii.a Small group learning activities

3.d.iii.b simulation skills training

3. e Informally supporting individualised learning.(19)

3.e.i.Clinicians are approachable, and learner centred

3.e.ii Good professional behaviour is modelled

3.e.iii Affective support is provided

3.e.iv Supervisors are respectful, open, friendly, kind and helpful

3.e.v Supervisors are inspiring and positive

3.e.vi Students are supported to feel part of the team

\section{Context intraindividual to the student}


4. -Personal identity: Who the student is before starting medical school may be relevant to how they experience a clerkship. This may be influenced by a mix of personal and social factors which are intertwined and will continue to influence their professional identity formation such as gender, race, personal characteristics, culture, and class $(57,64)$.Personal identity is foundational to an "individual's personal epistemologies (i.e. what individuals know, can do and value)" (58)(p. 129) which will influence how a learner engages with workplace learning. The personal epistemologies of the learner will influence their level of motivation and of agency to participate in workplace learning and are central to the outcomes of workplace learning (58).

Results Sect. 3 - Context-Mechanism-Outcome Configurations

Within the context of the RACF, curriculum delivery was designed to increase the likelihood that student learning would be enhanced. Aspects of curriculum delivery were often reported as leading to positive learning outcomes triggered by intraindividual mechanisms of affective learning, observing, and rehearsing skills, and a chance to think through clinical care decisions. Often contexts, mechanisms and outcomes acted in concert. Codes noted in results Sect. 2 are in italics.

Demi-regularities that were frequently reported by students:

\section{1) A structured programme enhanced learning:}

The curriculum deliverycontext of being welcomed and orientated within a highly structured programme outlining clear expectations for the clerkship, and organising the residents (real patients) the students were to engage with, triggered mechanisms of positive feelings (intra-individualaffective learning) as students engaged in the outcome of real patient learning, enhanced knowledge about many aspects of caring for RACF residents, practised new skills, and reported affective learning. (see supplementary file 2 for a list of student learning outcomes gleaned from the data).

\section{2) The programme supplied a useful adjunct to an acute care training focus in relation to care of elderly. frail patients:}

The curriculum context of the RACF and the programme taught (mechanism - intraindividual cognitive learning) students about many aspects of caring for elderly frail people that were missing from their usual clerkships such as knowledge (learning outcomes) about when not to take an acute care approach, the optimal care of those with dementia, the concept of deprescribing, the palliative approach to care, and how RACFs work.

\section{3) Being able to independently think about a resident's care lead to enjoyment of contributing to patient care:}

The context of the curriculum being aimed at the correct level of proficiency for their stage of training triggered the mechanism of independently think about a resident's current management plan with the 
dual outcomes of the enjoyment of contributing to patient care (affective learning) and of contributing to patient care.

\section{4) Respectfully considering a student's opinion on the care of a resident enhanced student sense of professional identity formation:}

Clinical supervisors who were respectful and open (context) to student suggestions on how to improve resident care triggered the mechanism of positive feelings (intra-individual affectivelearning) as the student's professional identity formation as a clinician was acknowledged (outcome). This was particularly the case if the student's management suggestions were adopted.

\section{5) Formal and informal support enhanced students' feeling.part of the team:}

The context of curriculum design of formally and informally supporting students led to the learning mechanisms of student (intra-individual affective learning) enjoyment of contributing to patient care and of feeling part of the team (outcome) caring for a resident. The formal and informal support from their clinical supervisor consisted of delivering feedback, briefing and debriefing students, delivering tutorials in small groups of four to five students, and being approachable, respectful and open towards students.

\section{6) Medical student experience of interprofessional practice was positively regarded:}

In the context of medical and nursing students collaborating to assess a resident the medical students reflected (mechanism - learning by thinking) that interprofessional practice (IPP) was enjoyable and regretted if not experienced (outcome - affective learning). Other outcomes were improved knowledge about the particular knowledge and skills nurses possess.

In the context of a GP, registered nurse, physiotherapist and/or pharmacist considering the care of residents medical students observed or engaged in (mechanism - learning by doing) IPP leading to learning about new strategies (outcome-knowledge) to care for residents.

Less frequently noted CMOCs but useful in theory conceptual development:

\section{7) Time enough to learn was valued:}

Being given the context of enough time for optimal learning led to mechanisms of (intra-individual affective learning) enjoyment of the learning experience as students had time to reflect with peers as learning outcomes were achieved.

\section{8) Student personal identity informs negative attitude towards programme:}

That the context of caring for those in a RACF who are in gradual physical and cognitive decline and the context of a student's personal identity of their future medical role led to a mechanism of negative intraindividual affective emotion leading to an affective learningoutcome of disliking the RACF clerkship. 


\section{9) Student professional identity informs negative attitude towards programme:}

The RACF programme context was seen as not sequenced appropriately in the training continuum of some students who felt (mechanismintraindividual affective learning) it would not prepare them to work in acute care settings on graduation i.e. did not fit with their socialised professional identity learning outcome. This $\mathrm{CMOC}$ became more frequent the closer the clerkship was to students' graduation from their medical degree.

\section{Discussion}

Proposal of a realist theory of experience-based learning

Dornan et al's ExBL (19) has proven useful as a theoretical framework congruent with many aspects of the RACF clerkship programme theory though lacking in a perspective relevant to the intraindividual perspective of the student learner. This discussion focuses first on general conceptual issues then on the particular findings of our research as a final realist theory of experience-based learning informed by a realist analysis of the student perspective, is presented.

Reviewing the conceptualisation of human thought and the structure of knowledge within education and more recently within health professional education reveals an evolution from concentrating only on the cognitive aspect of learning, then the inclusion of a learner's emotions and affect, as knowledge and psychomotor skills are developed (65). The intimate effect of the sociocultural environment on the individual learner is also now appreciated (24).

When Bloom et al (1956) devised a taxonomy of cognitive domain educational objectives (66) devising a taxonomy of affective domain objectives was noted as a difficult task perhaps explaining the eight years it took for Krathwohl et al (1964) to add the affective domain to this body of work (67). Krathwohl et al defined the affective domain objectives as those "which emphasize a feeling tone, an emotion, a degree of acceptance or rejection. Affective objectives vary from the simple attention to selected phenomena to complex but internally consistent qualities of character and conscience."(67)(P.7)

Affective learning is the acquisition of affective domain objectives and in health professional education is most often equated with the process of a learner acquiring professional values (68).

Affective learning outcomes can be inward looking to a student's confidence, motivation, emotional intelligence and their sense of professional identity, or be concerned with the student in relation to others such as their demonstration of compassion and empathy, cultural competence, team-member qualities, leadership ability, and ultimately their professionalism $(19,69)$.

Health professional education has been slow to explicitly incorporate the affective domain into learning objectives with efforts to assess this domain formalised in the last two decades, predominantly based on observed behaviours of learners (70). The ethical dilemma of eliciting a student's private affective learning versus their observed professional behaviour has been acknowledged but increasingly health 
professional education aims to produce a student who is a professional not just one who can act like one $(69,71)$.

Recently Krathwohl et al's (1964) taxonomy of affective learning objectives have been used to research the process of affective learning (68). This approach could inform future assessment of health professional students' affective learning beyond the merely observed, and also complement the theorisation of professional identity formation (63).

Further to the process of affective learning and stepping from a framework to a learning theory Marzano and Kendall (2007) built upon Bloom's taxonomy adding metacognition to the cognitive in their taxonomy of educational objectives (65). The metacognitive system monitors and increases the efficiency of the cognitive system encompassing an awareness of one's own thoughts, emotions, and performance, and an ability to interpret the mental states of others, and situations (72). Reflection is a metacognitive activity (72) and is one of the few activities, if reported to others, that can lead to the recognition of the often implicit activity of affective learning $(68,73)$.

However, both Bloom (1956), and Marzano and Kendall's (2007) taxonomies are criticised for intimating a linear theory of learning given that learning is acknowledged to be non-linear, emergent and dynamic in nature (74).

In health professional education earlier research of learning processes has been orientated towards the cognitive domain (75), while more recent empirical studies involving simulation-based learning are starting to incorporate or focus on the more challenging to conceptualise affective domain $(68,76,77)$.

Learning processes are now mostly theorised to involve many conceptual components within (intraindividual), and outside the learner i.e. the social context including the hidden curriculum (78). In more recent times most conceptual models of how learning takes place within education generally, and health professional education specifically, incorporate feedback loops and intersecting areas acknowledging the non-linear, dynamic and emergent nature of learning $(55,73,75,77,79-81)$.

Aspects of student thinking (cognition), emotional reaction or intraindividual affective learning and the activities they were undertaking (behaviours) whilst on the RACF placement prompt the inclusion in the conceptual model of the learning theory-based view that all are mutually reliant on each other for an effective learning outcome $(60,79,82,83)$.

Over the last 50 years learning theory-based cognitive behaviour therapy has visually illustrated the relationships between intraindividual elements as an aid in psychoeducation of people as they learn how to manage their emotions, cognitions, behaviours and physical health to improve their overall wellbeing (84). It is useful to adapt this model to represent the intraindividual aspects of a realist theory of experience-based learning presented in figure two.

Figure 2 inserted here 
Not all aspects of this theory are findings of this study. Aspects that could be found in future research are represented in lighter shades of grey. For example, in a future study the RACF student clerkship could be used to explore a link between a student's underlying temperament (85) and their sense of professional identity.

Strengths, limitations, and future direction for the RACF clerkship

The RACF clerkship was appreciated as a good quality experience offering a chance for students to engage in authentic and meaningful learning (86) in a supportive environment leading to enhanced clinical skills as they prepared to become junior doctors. Students were given time to think as clinicians as they participated in patient care, and their professional identity as clinicians was legitimised by their engagement with their GP supervisor (87). It is likely this sort of experience assists in their identity transition to internship (88) although some students did not perceive this due to the context of non-acute care.

A limitation of this work is the context-specific nature of the RACF clerkship though this may also be a strength as it has prompted student reflection on their more traditional hospital-based clerkships leading to the development of the final realist programme theory. Undertaking research in a clerkship conducted outside the traditional hospital ward has resulted in learner-perspective findings that describe not only the positive and negative attributes of a RACF clerkship but also those provided by hospital clerkships. This type of prompt to reflection on hospital clerkships has been previously described in relation to the general practice setting (89). It also highlights the aspect of professional identity formation as students located their experience in the perceptions of their impending role as an intern or other future clinician, also described in relation to senior medical students in the general practice setting (89).

Comparison to existing literature

While Dornan et al's (2014) mid-range ExBL theory has been used to investigate students' needs during a clerkship (90) this is the first realist evaluation using Dornan et al's ExBL framework (19). In particular, this realist analysis focuses on the perspective of the student learner leading to the conceptual development of intraindividual aspects of learning as part of the ExBL framework. Other health professional education researchers have recognised the intraindividual context of the learner in their realist evaluations in relation to medical student workplace-based assessment (91), and workplace preparedness as senior medical students or junior doctors graduated to take on more responsibility (92) but not placed them in an overall realist programme theory.

While this work has concentrated on the intraindividual world of the student leading to a modification of the ExBL mid-range theory it is also congruent with more socio-cultural perspectives $(23,89)$ with the inclusion and clarification of the context for learning and its effect on the learner. Therefore, this work brings the sociocultural and experiential learning theories closer together. The context of the RACF clerkship assisted in elaborating sociocultural learning because students often reflected on the contrast with their usual acute-care hospital-based clerkships (89). 
Very few countries or medical schools provide clinical placements in RACFs (1) with the Netherlands one of those countries. A Dutch programme also found that students learnt of the unique aspects of patient care less likely to be encountered in acute care practice such as when not to take an acute care approach to the care of frail elderly people, the optimal care of those with dementia, the concept of deprescribing, the palliative approach to care, and how RACFs work (14).

Because the RACF closely scaffolded the clinical activities and degree of autonomy of each learner (46) we argue it could prove suitable for the assessment of entrustable professional activities at levels of supervision relevant to graduation into internship (88). An area for future research.

\section{Conclusions}

This paper provides a realist evaluation of a clerkship undertaken in a residential aged care facility by senior medical students leading to a programme theory for experience-based learning that may prove useful in the evaluation of student perspectives of clerkships more generally. Of note are the inclusion of the intraindividual perspective of the learner and the inclusion of professional identity formation (56) as an added feature of experience-based learning frameworks in medical education.

A clerkship in residential aged care provided students, who will be transitioning to internship the following year, with unique learning opportunities, and a chance to develop their professional identities as clinicians. Most students enjoyed this challenge, but a small number found it difficult to assimilate their personal identity or future professional identity with caring for elderly frail people in residential aged care.

\section{Abbreviations}

CMOCs

context mechanism outcome configurations

Ex-BL

experience-based learning

\section{Declarations}

\section{Funding}

The RACF programme described in the paper was delivered as part of Health Workforce Australia funded by the Australian Federal Government.

\section{Competing interests}

The authors have no conflicts of interest to declare.

\section{Author contribution}


Author JR and AT developed the clerkship that was evaluated from the students' perspective. Author AT assisted in the delivery of the clerkship programme within the RACF. Authors JR and MB developed the data collection tools. Author MB conducted the focus group interviews. Author JR initially analysed data before collaborating with AT and MB to finalise analysis. Author JR drafted the manuscript which was revised by authors AT and MB. All authors have read and approved the manuscript.

\section{Acknowledgments}

The authors would like to acknowledge the Wicking Dementia Research and Education Centre, University of Tasmania; Prof James Vickers; Adjunct Prof Andrew Robinson; Dr Elaine Crisp; Newstead Medical; Dr Jane Fuller; Masonic Care Tasmania: Peacehaven Home and Fred French Home.

\section{Availability of data and materials}

Supporting data can be obtained from first author on reasonable request.

\section{Consent for publication}

Consent to publish was obtained from study participants in writing.

\section{References}

1. Radford J, Dallas A, Ramsay R, Robin E, Todd A. Medical students in residential aged care: A guide. Clin Teach. 2020;17(n/a):1-7.

2. Pawson R, Tilley N. Realistic Evaluation. London: SAGE; 1997.

3. Morley JE. Clinical practice in nursing homes as a key for progress. Journal of Nutrition Health Aging. 2010;14(7):586.

4. Butler R. The teaching nursing home. JAMA. 1981;245:1435-7.

5. Schneider EL, Ory M, Aung ML. Teaching nursing homes revisited: Survey of affiliations between american medical schools and long-term-care facilities. JAMA. 1987;257(20):2771-5.

6. Katz P, Karunza J, Counsell S. Academics and the nursing home. Clin Geriatr Med. 1995;11(3):50313.

7. Wiener M, Shamaskin A. The nursing home as a site for teaching medical students. Acad Med. 1990;65(6):412-4.

8. Rosenthal MJ, Marshall CE, Martin SE, Morley JE, Ouslander JG. Nursing home rounds as a format for teaching residents and medical students. Acad Med. 1987;62(12):975-80.

9. Wener S, Foley C, Jaffe A. Three years of a required geriatrics module for third-year medical students. Acad Med. 1991;66(5):292-4.

10. Mezey MD, Mitty EL, Burger SG. Rethinking Teaching Nursing Homes: Potential for Improving LongTerm Care. Gerontologist. 2008;48(1):8-15. 
11. Kanter SL. The Nursing Home as a Core Site for Educating Residents and Medical Students. Acad Med. 2012;87(5):547-8. 10.1097/ACM.0b013e3182557445.

12. Lee J, Cioltan H, Goldsmith P, Heasley B, Dermody M, Fain M, et al. An assisted living interprofessional education and practice geriatric screening clinic (IPEP-GSC): a description and evaluation. Gerontology \& Geriatrics Education. 2018:1-12.

13. Helmich E, Bolhuis S, Prins J, Laan R, Koopmans R. Emotional learning of undergraduate medical students in an early nursing attachment in a hospital or nursing home. Med Teach. 2011;33(11):e593-601.

14. Huls M, de Rooij SE, Diepstraten A, Koopmans R, Helmich E. Learning to care for older patients: hospitals and nursing homes as learning environments. Med Educ. 2015;49(3):332-9.

15. Barnett K, Abbey J, Eyre J. Implementing the Teaching Nursing Homes Initiative: Scoping Study. Australian Institute for Social Research; 2011.

16. Saunders R, Miller K, Dugmore H, Etherton-Beer C. Demystifying aged care for medical students. Clin Teach. 2017;14(2):100-3.

17. Kent F, Nickson W, Molloy E, Keating J. Expanding aged care clinical education. Clin Teach. 2016;13(2):152-5.

18. Dornan T, Boshuizen H, King N, Scherpbier A. Experience-based learning: a model linking the processes and outcomes of medical students' workplace learning. Med Educ. 2007;41(1):84-91.

19. Dornan T, Tan N, Boshuizen H, Gick R, Isba R, Mann K, et al. How and what do medical students learn in clerkships? Experience based learning (ExBL). Adv Health Sci Educ Theory Pract. 2014;19(5):72149.

20. Wong G, Greenhalgh T, Westhorp G, Pawson R. Realist methods in medical education research: what are they and what can they contribute? Med Educ. 2012;46(1):89-96.

21. Jagosh J, Macaulay AC, Pluye P, Salsberg J, Bush PL, Henderson J, et al. Uncovering the Benefits of Participatory Research: Implications of a Realist Review for Health Research and Practice. Milbank Q. 2012;90.

22. Wong G, Westhorp G, Greenhalgh J, Manzano A, Jagosh J, Greenhalgh T. Quality and reporting standards, resources, training materials and information for realist evaluation: the RAMESES II project. Health Services Delivery Research. 2017;5(28):1-134.

23. Lave J, Wenger E. Situated learning: legitimate peripheral participation. Seely Brown J, editor. Cambridge: Cambridge University Press; 1991.

24. Wenger E. Communities of practice: learning, meaning, and identity. 1st ed. Brown S J, editor. Cambridge: Cambridge University Press; 1998. 318 p.

25. Cruess RLMD, Cruess SRMD, Steinert YP. Medicine as a Community of Practice: Implications for Medical Education. Acad Med. 2018;93(2):185-91.

26. Saldana J. The Coding Manual for Qualitative Researchers. 3 ed. London: Sage; 2016. 
27. Teunissen PW, Kogan J, ten Cate O, Gruppen L, Lingard L. Learning in Practice: A Valuation of Context in Time-Variable Medical Training. Acad Med. 2018;93(3):22-6.

28. Bates J, Ellaway RH. Mapping the dark matter of context: a conceptual scoping review. Med Educ. 2016;50(8):807-16.

29. Astbury B, Leeuw FL. Unpacking Black Boxes: Mechanisms and Theory Building in Evaluation. American Journal of Evaluation. 2010;31(3):363-81.

30. Dalkin S, Greenhalgh J, Jones D, Cunningham B, Lhussier M. What's in a mechanism? Development of a key concept in realist evaluation. Implement Sci. 2015;10.

31. Lacouture A, Breton E, Guichard A, Ridde V. The concept of mechanism from a realist approach: a scoping review to facilitate its operationalization in public health program evaluation. Implementation Science: IS. 2015;10:153.

32. Sorinola OO, Thistlethwaite J, Davies D, Peile E. Realist evaluation of faculty development for medical educators: What works for whom and why in the long-term. Med Teach. 2017;39(4):422-9.

33. Haji F, Morin M-P, Parker K. Rethinking programme evaluation in health professions education: beyond 'did it work?'. Med Educ. 2013;47(4):342-51.

34. Australian Institute of Health and Welfare. Residential Aged care in Australia 2009-10: a statistical overview. Aged care statistics. Canberra: Australian Institute of Health and Welfare; 2011.

35. Reed R. Models of general practitioner services in residential aged care facilities. Aust Fam Physician. 2015;44:176-9.

36. Royal Commission into Aged Care Quality and Safety. Royal Commission into Aged Care Quality and Safety: Interim Report Canberra: Coomonwealth of Australia; 2019.

37. O'Connell B, Hawkins M, Considine J, Au C. Referrals to hospital emergency departments from residential aged care facilities: Stuck in a time warp. Contemporary Nurse: A Journal for the Australian Nursing Profession. 2013;45(2):228-33.

38. Gadzhanova S, Reed R. Medical services provided by general practitioners in residential aged-care facilities in Australia. Med J Aust. 2007;187(2):92-4.

39. O'Halloran J, Britt H, Valenti L. General practitioner consultations at residential aged-care facilities. Med J Aust. 2007;187(2):88-91.

40. Pearson R, Mullan J, Ujvary E, Bonney A, Dijkmans-Hadley B. Australian general practitioner attitudes to residential aged care facility visiting. Health Social Care in the Community. 2018;26(4):e497-504.

41. Radford J. Residential aged care facility residents: training issues for Australian general practitioners. Aust Fam Physician. 2015;44(1):2.

42. RACGP. Medical care of older persons in residential aged care facilities. Melbourne: Royal Australian College of General Practitioners; 2006. Available from: http://www.racgp.org.au/yourpractice/guidelines/silverbook/.

43. Australian Government Department of Health and Ageing. Guidelines for a Palliative Approach for Aged Care in the Community Setting. Australian Government Department of Health and Aging; 2011. 
44. Royal Australian College of General Practitioners. Royal Australian College of General Practitioners (RACGP) Curriculum. Melbourne: RACGP; 2007.

45. Robinson A, See C, Lea E, Bramble M, Andrews S, Marlow A, et al. Wicking teaching aged care facilities program: Innovative Practice. Dementia. 2017;16(5):673-81.

46. Morris C, Blaney D. Work-based learning. In: Swanick T, editor. Understanding Medical Education: Evidence, Theory and Practice. London: Wiley-Blackwell; 2010.

47. Microsoft Corporation. Microsoft Excel. Microsoft Corporation; 2020.

48. The RAMESES II Project. Retroduction in realist evaluation2017 15 June 2020. Available from: https://www.ramesesproject.org/media/RAMESES_II_Retroduction.pdf.

49. Wong G, Westhorp G, Manzano A, Greenhalgh J, Jagosh J, Greenhalgh T. RAMESES II reporting standards for realist evaluations. BMC Med. 2016;14(1):96.

50. O'Brien BC, Harris IB, Beckman TJ, Reed DA, Cook DA. Standards for Reporting Qualitative Research: A Synthesis of Recommendations. Acad Med. 2014;89(9):1245-51.

51. Mann K, Gordon J, MacLeod A. Reflection and reflective practice in health professions education: a systematic review. Adv Health Sci Educ Theory Pract. 2007;14(4):595.

52. Marsh C. Key Concepts for Understanding Curriculum. 4th ed. Goodson I, editor. Oxon: Routledge; 2009.

53. Fish D, Coles C. Medical Education: Developing a curriculum for practice: Open University Press; 2005.

54. Bleakley A, Bligh J, Browne J. Medical Education for the Future: Identity, Power and Location. 1st ed. Hamstra S, editor: Springer; 2011.

55. Tarricone P. The Taxonomy of Metacognition. Hove: Psychology Press; 2011.

56. Cruess SR, Cruess RL, Steinert Y. Supporting the development of a professional identity: General principles. Med Teach. 2019;41(6):641-9.

57. Cruess RLMD, Cruess SRMD, Boudreau JDMD, Snell LMDM, Steinert YP. A Schematic Representation of the Professional Identity Formation and Socialization of Medical Students and Residents: A Guide for Medical Educators. Acad Med. 2015;90(6):718-25.

58. Billett S. Learning through health care work: premises, contributions and practices. Med Educ. 2016;50(1):124-31.

59. Lewin LO, McManamon A, Stein MTO, Chen DT. Minding the Form That Transforms: Using Kegan's Model of Adult Development to Understand Personal and Professional Identity Formation in Medicine. Acad Med. 2019;94(9):1299-304.

60. Nguyen QD, Fernandez N, Karsenti T, Charlin B. What is reflection? A conceptual analysis of major definitions and a proposal of a five-component model. Med Educ. 2014;48(12):1176-89.

61. Bloom BS. Taxonomy of educational objectives. New York: Mckay; 1956.

62. Jarvis-Selinger $S$, Practt $D$, Regehr G. Competency is not enough: integrating identity formation into the medical education discourse. Acad Med. 2011;87(9):1185-90. 
63. Cruess RLMD, Cruess SRMD, Boudreau JDMD, Snell LMDM, Steinert YP. Reframing Medical Education to Support Professional Identity Formation. Acad Med. 2014;89(11):1446-51.

64. Volpe RL, Hopkins M, Haidet P, Wolpaw DR, Adams NE. Is research on professional identity formation biased? Early insights from a scoping review and metasynthesis. Med Educ. 2019;53(2):119-32.

65. Marzano R, Kendall J. The New Taxonomy of Educational Objectives. 2nd ed. Thousand Oaks: Corwin Press, A Sage Publication Company; 2007.

66. Bloom B, Engelhart M, Furst E, Hill W, Krathwohl D. Handbook I. Cognitive Domain. Taxonomy of Educational Objectives: The Classification of Educational Goals. New York: David McKay Company, Inc; 1956.

67. Krathwohl D, Bloom B, Masia B. Handbook II. Affective Domain. Taxonomy of Educational Objectives, The Classification of Educational Goals. New York: David McKay Company, Inc; 1964.

68. Rogers GD, Mey A, Chan PC. Development of a phenomenologically derived method to assess affective learning in student journals following impactive educational experiences. Med Teach. 2017;39(12):1250-60.

69. Al-Eraky M, Marei H. A fresh look at Miller's pyramid: assessment at the 'Is' and 'Do' levels. Med Educ. 2016;50(12):1253-7.

70. Cate TJt, De Haes JCJM. Summative assessment of medical students in the affective domain. Med Teach. 2000;22(1):40-3.

71. Cruess RLMD, Cruess SRMD, Steinert YP. Amending Miller's Pyramid to Include Professional Identity Formation. Acad Med. 2016;91(2):180-5.

72. Craig K, Hale D, Grainger C, Stewart ME. Evaluating metacognitive self-reports: systematic reviews of the value of self-report in metacognitive research. Metacognition and Learning. 2020.

73. Pagatpatan CP, Valdezco JAT, Lauron JDC. Teaching the affective domain in community-based medical education: A scoping review. Med Teach. 2020;42(5):507-14.

74. Irvine J. A comparison of revised Bloom and Marzano's New Taxonomy of Learning. Research in Higher Education Journal. 2017;33(Nov).

75. Teunissen PW, Scheele F, Scherpbier AJJA, van der Vleuten CPM, Boor K, van Luijk SJ, et al. How residents learn: qualitative evidence for the pivotal role of clinical activities. Med Educ. 2007;41(8):763-70.

76. Fraser K, Ma I, Teteris E, Baxter H, Wright B, McLaughlin K. Emotion, cognitive load and learning outcomes during simulation training. Med Educ. 2012;46(11):1055-62.

77. Torres A, Horodeńska M, Witkowski G, Torres K. Hybrid simulation of pediatric gynecologic examination: a mix-methods study of learners' attitudes and factors affecting learning. BMC Med Educ. 2020;20(1):164.

78. Snyder B. The hidden curriculum. New York: Knopf; 1977.

79. Hayat AA, Shateri K, Amini M, Shokrpour N. Relationships between academic self-efficacy, learningrelated emotions, and metacognitive learning strategies with academic performance in medical 
students: a structural equation model. BMC Med Educ. 2020;20(1):76.

80. Ben-Eliyahu A. Academic Emotional Learning: A Critical Component of Self-Regulated Learning in the Emotional Learning Cycle. Educ Psychol. 2019;54(2):84-105.

81. Lajoie SP, Zheng J, Li S, Jarrell A, Gube M. Examining the interplay of affect and self regulation in the context of clinical reasoning. Learning and Instruction. 2019:101219.

82. Pekrun R, Goetz T, Titz W, Perry RP. Academic Emotions in Students' Self-Regulated Learning and Achievement: A Program of Qualitative and Quantitative Research. Educ Psychol. 2002;37(2):91105.

83. LeBlanc VR, McConnell MM, Monteiro SD. Predictable chaos: a review of the effects of emotions on attention, memory and decision making. Adv Health Sci Educ Theory Pract. 2015;20(1):265-82.

84. Padesky CA, Mooney KA. Clinical tips: Presenting the cognitive model to clients. International Cognitive Therapy Newsletter. 1990;6:13-4.

85. Eley DS, Leung J, Hong BA, Cloninger KM, Cloninger CR. Identifying the Dominant Personality Profiles in Medical Students: Implications for Their Well-Being and Resilience. PLoS One. 2016;11(8):e0160028.

86. Yardley S, Westerman M, Bartlett M, Walton JM, Smith J, Peile E. The do's, don't and don't knows of supporting transition to more independent practice. Perspect Med Educ. 2018;7(1):8-22.

87. Steven K, Wenger E, Boshuizen H, Scherpbier A, Dornan T. How clerkship students learn from real patients in practice settings. Acad Med. 2014;89.

88. Yardley S, Kinston R, Lefroy J, Gay S, McKinley RK. 'What do we do, doctor?' Transitions of identity and responsibility: a narrative analysis. Adv Health Sci Educ Theory Pract. 2020.

89. van der Zwet J, Zwietering PJ, Teunissen PW, Vleuten CPM, Scherpbier AJJA. Workplace learning from a socio-cultural perspective: creating developmental space during the general practice clerkship. Adv Health Sci Educ Theory Pract. 2011;16(3):359-73.

90. Barrett J, Trumble SC, McColl G. Novice students navigating the clinical environment in an early medical clerkship. Med Educ. 2017;51(10):1014-24.

91. Lefroy J, Hawarden A, Gay SP, McKinley RK, Cleland J. Grades in formative workplace-based assessment: a study of what works for whom and why. Med Educ. 2015;49(3):307-20.

92. Lefroy J, Yardley S, Kinston R, Gay S, McBain S, McKinley R. Qualitative research using realist evaluation to explain preparedness for doctors' memorable 'firsts'. Med Educ. 2017;51(10):1037-48.

\section{Figures}




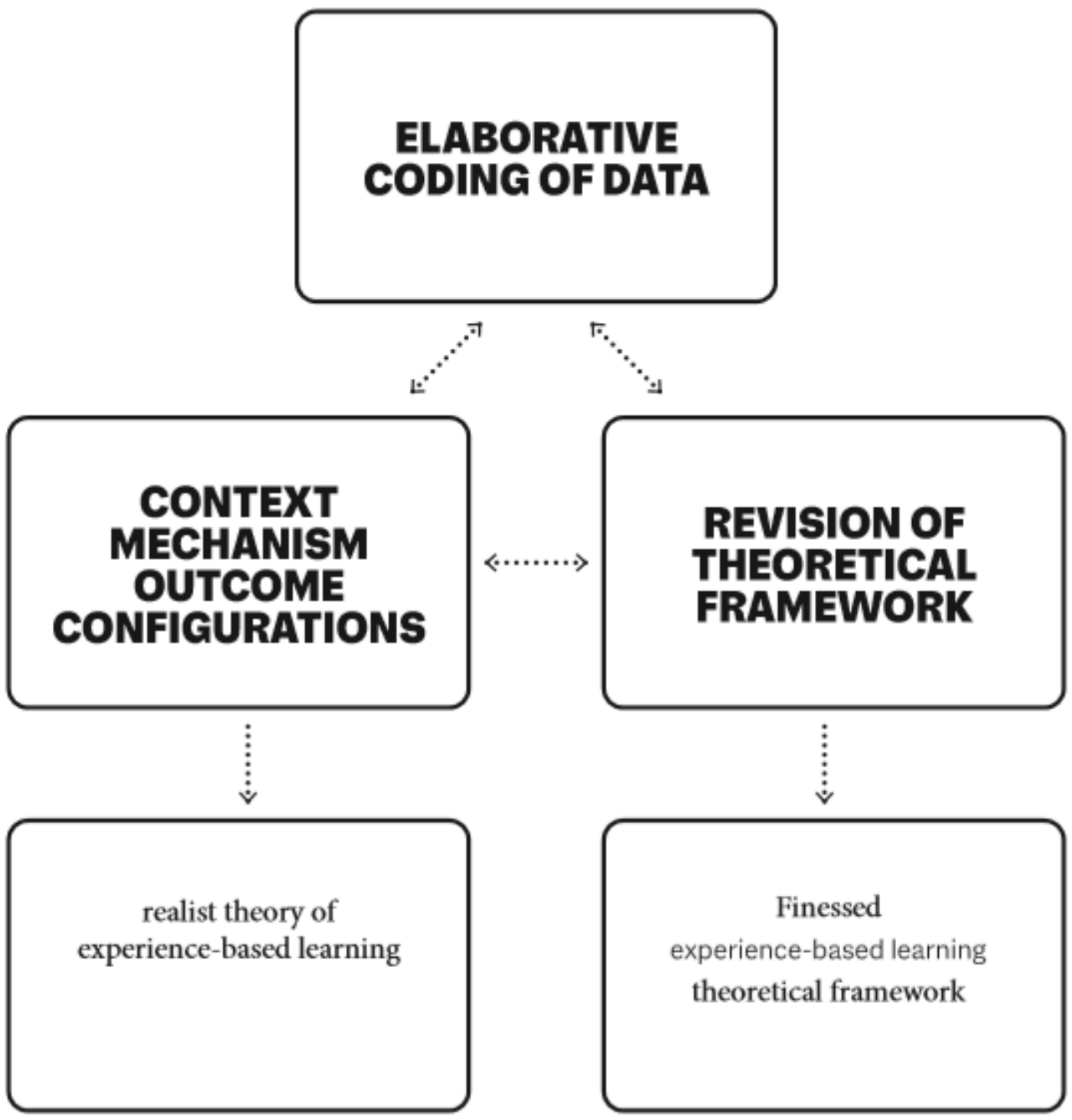

Figure 1

Data analysis process and outcomes 


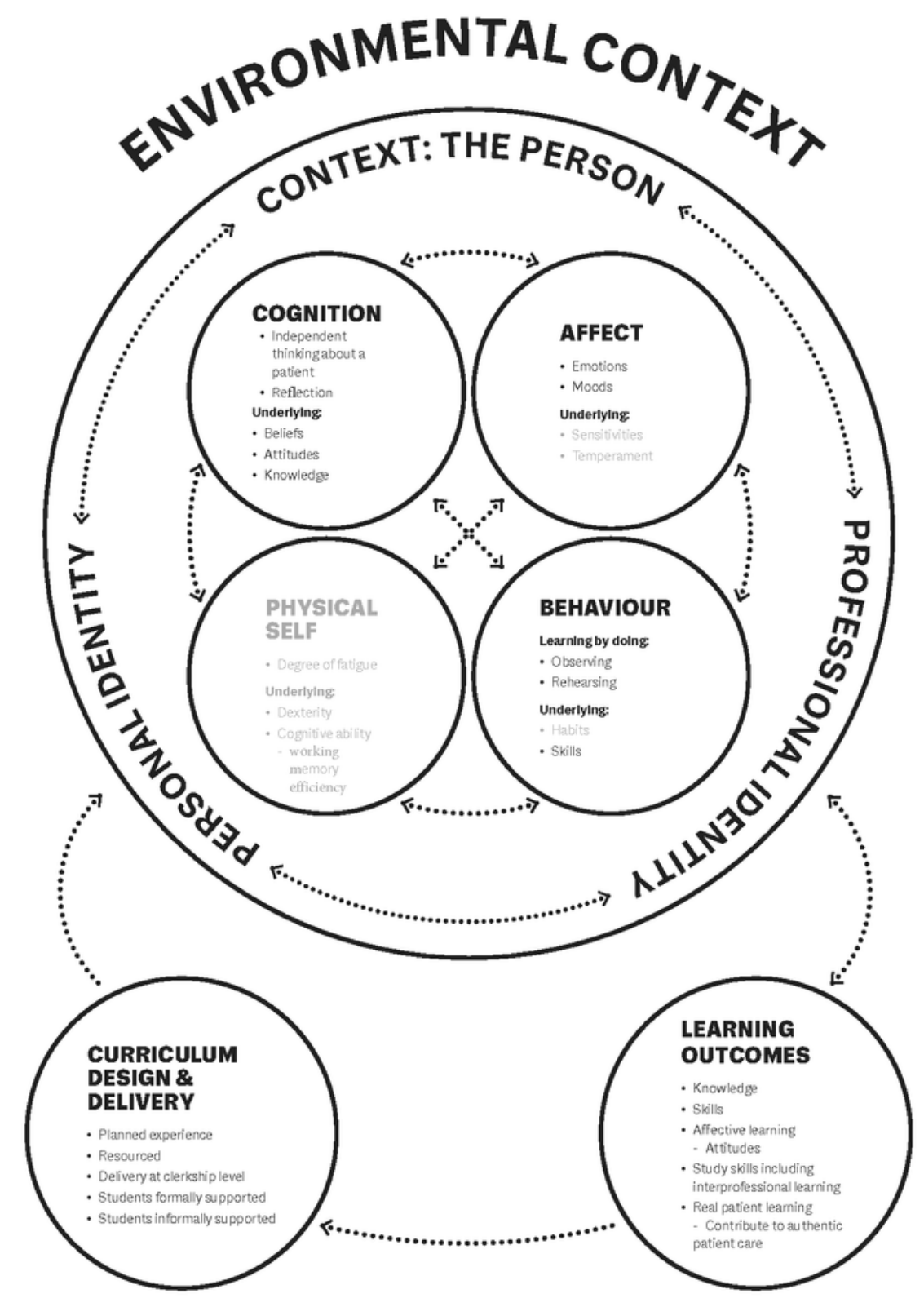

FOR LEARNING

Figure 2

The intraindividual aspects of a realist theory of experience-based learning

\section{Supplementary Files}

This is a list of supplementary files associated with this preprint. Click to download. 
- Glossary.RealistEvalofRACFclerkshipRadford.docx

- Supplementaryfile1ExBLcodesOct2020.docx

- Supplementaryfile2listofLOs.docx 